\title{
ASSEMBLY LiNe BALANCING
}

\section{MicietA, B. \& StOLLMANN,V.}

Abstract: The development of the assembly line revolutionized manufacturing, and contributed to the higher level of Industrial Revolution. Assembly lines are designed for a sequential organization of workers, tools or machines, and parts. The motion of workers is minimized to the extent possible. All parts or assemblies are handled either by conveyors or motorized vehicles such as fork lifts, or gravity, with no manual trucking. The main goal is to minimize the number of workstation of the line, but additional goals are also envisaged. Article describe goal and, boundaries of assembly line balancing with focus on new algorithms research. Assembly line is suitable for mass production of standardized products. Assembly line allows increase considerably productivity and competitiveness of manufacturers .

Key words: assembly line balancing, ACO, genetic algorithm, assembly line problems
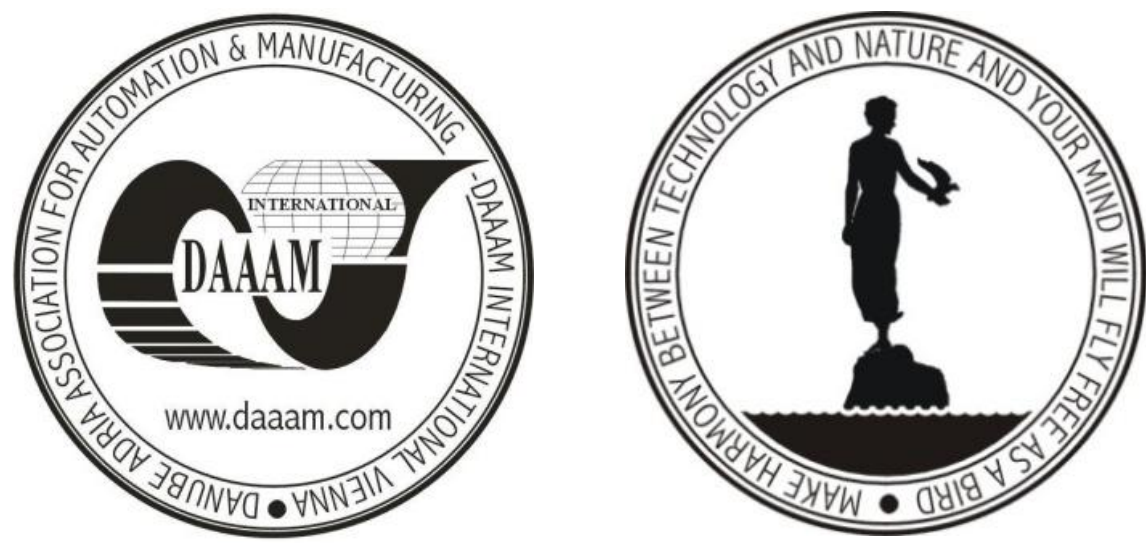

Authors' data: Univ. Prof. Dipl.-Ing. Micieta, B[ranislav]*; Dipl.-Ing. Stollmann, V[ladimir]**, *University of Zilina, Univerzitná 8215/1, 010 26, Žilina, Slovakia, *** Technical university in Zvolen, Študentská ulica 26, 96053 Zvolen, Slovakia, branislav.micieta@fstroj.uniza.sk, stollmann@vsld.tuzvo.sk

This Publication has to be referred as: Micieta, B[ranislav] \& Stollmann, V[ladimir] (2011). Assembly Line Balancing, Chapter 21 in DAAAM International Scientific Book 2011, pp. 257-264, B. Katalinic (Ed.), Published by DAAAM International, ISBN 978-3-901509-84-1, ISSN 1726-9687, Vienna, Austria DOI: $10.2507 /$ daaam.scibook.2011.21 


\section{Introduction}

Before the advent of the assembly line, when a commercial good was manufactured, it was usually created by hand, from individually fabricated parts. An assembly line is suitable for a type of industrial production in which prefabricated, interchangeable parts are used to assemble a finished product (Zelenka 2010). The most assembly line consists of a simple conveyor belt (more complex one include feeder belts) which carries the product, through a series of work stations until it is finished. The development of the assembly line revolutionized manufacturing, and contributed to the higher level of Industrial Revolution.

Ford conceived of a production line, where the labor of workers would be divided into specific tasks which would contribute to the finished whole. The inspiration for this early assembly line likely came from several industries, but many historians credit the disassembly line at a Chicago slaughterhouse with the idea of dividing the labor.

Ever since Henry Ford's introduction of assembly lines, Line balancing has been an optimization problem of significant industrial importance: the efficiency difference between an optimal and a sub-optimal assignment can yield economies (or waste) reaching millions of dollars per year. Decreased costs of production allowed lower prices of manufactured goods, better competitiveness of enterprises, and better exploitation of the market's potential.

\section{Main types of assembly lines}

There are many types of assembly line systems, some common variations include the classic, automated, intermittent and lean manufacturing models. These assembly line systems are often used for making different types of products. Assembly lines have some shared characteristics. Fig. 1 summarizes the kinds of assembly systems.

\begin{tabular}{|c|c|c|c|}
\hline number of models & single model & mixed model & multi model \\
\hline line control & paced & unpaced asynchronous & unpaced synchronous \\
\hline frequency & \multicolumn{2}{|c|}{ first-time installation } & reconfiguration \\
\hline level of automation & manual lines & \multicolumn{2}{|c|}{ automated lines } \\
\hline line of business & automobile production & action & further examples \\
\hline
\end{tabular}

Fig. 1. Kinds of assembly systems (Boysen, 2006)

\subsection{Single model assembly line}

Single model assembly line is a type of assembly line in which assemblers work on the same product. Many publications are available concerning the design, balancing and scheduling for Single, Multi and Mixed-Product lines. The single- 
model assembly line is often not efficient for today's competitive industry because to respond the customer's expectation, companies need to produce mixed-model products.

\subsection{Mixed Model assembly line}

In mixed-model production is the practice of assembling several distinct models of a product on the same assembly line without changeovers and then sequencing those models in a way that smoothes the demand for upstream components. Setup times between models could be reduced sufficiently enough to be ignored, so that intermixed model sequences can be assembled on the same line. In spite of the tremendous efforts to make production systems more versatile, this usually requires very homogeneous production processes.

The objective is to smooth demand on upstream workcenters, manufacturing cells or suppliers and thereby reduce inventory, eliminate changeovers, improve kanban operation. It also eliminates difficult assembly line changeovers.

The Mixed-Model Assembly Line (MMAL) is a more complex to balance in which several types of the products are assembled simultaneously on the line which considering to the shape of line.

\subsection{Multi Product Assembly lines}

Multi-product production supports process manufacturers where multiple or single components are run through a processing line which delivers multiple end items or finished products, including waste or by-products. Serial/Lot control for components and end items is available, as are a variety of costing and yield methods.

\subsection{Peaced and unpeaced assembly lines}

In peaced assembly systems a fixed time value restricts the work content of stations (SALB further assumes that the cycle time of all stations is equal to the same value). Assembly lines with this attribute are called paced, as all stations can begin with their operations at the same point in time and also pass on workpieces at the same rate.

As a consequence, all station times of a feasible balance may never exceed cycle time, as otherwise the required operations could not be completed before the workpiece leaves the station (Boysen, 2007) .

These assembly lines thus have a fixed production rate, which is equal to the reciprocal of the cycle time. Under certain conditions, it might be required that cycle times are just kept on average (e.g. mixed-model lines, parallel line elements) or with a certain given probability (e.g. stochastic task times).

Station times can however be smaller than the cycle time, in which case a station $\mathrm{k}$ has an unproductive idle time of cycle time - time units in each cycle.

In unpaced lines, workpieces do not need to wait until a predetermined time span is elapsed, but are rather transferred when the required operations are finished. This type of line control is often implemented if stochastic variations influence processing times. For example, a massive body of literature covers the buffer allocation problem in unpaced asynchronous lines. Depending on the connection of 
the movements, two cases have to be distinguished (Buzacott \& Shanthikumar, 1993).

- In the synchronous case, workpieces are moved as soon as all stations have finished their operations.

- Under asynchronous movement, a station passes on its workpiece as soon as it has finished all operations as long as the successor is not blocked by another workpiece. Stations which finish early must thus wait until the station with the highest work content has completed its operations. In order to reduce waiting times due to blocking or starving stations, typically buffer storages are installed along the line. Thus, the ALB is accompanied by the additional decision problem of positioning and dimensioning buffers (Dolgui et al., 2002).

\section{Assembly line objectives}

Assembly Line Balancing (ALB) is a classic operations research problem. Since the first mathematical formalization of ALB by Salveson (1955), academic work mainly focused on the core problem of the configuration, which is the assignment of tasks to stations. Most of the research in assembly line balancing has been devoted to modeling and solving the simple assembly line balancing problem (SALBP).

Four versions are defined by using different objectives (Scholl, 1999): SALBPE maximizes the line efficiency E, SALBP-1 minimizes the number of stations $(m)$ given the cycle time $c$, SALBP-2 minimizes cycle time given $m$, while SALBP-F seeks for a feasible solution given number of workstations and cycle time (Fig. 2.). A recent survey of solution procedures for these basic problems is given by Scholl and Becker (2006).

\begin{tabular}{|c|c|c|c|}
\hline & \multicolumn{2}{|c|}{ cycle time c } \\
\hline & & given & minimize \\
\hline \multirow{2}{*}{ 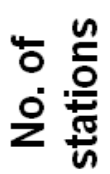 } & given & SALBP-F & SALBP-2 \\
\hline & minimize & SALBP-1 & SALBP-E \\
\hline
\end{tabular}

Fig. 2. Four version of simple assembly line balancing (Scholl, 1999)

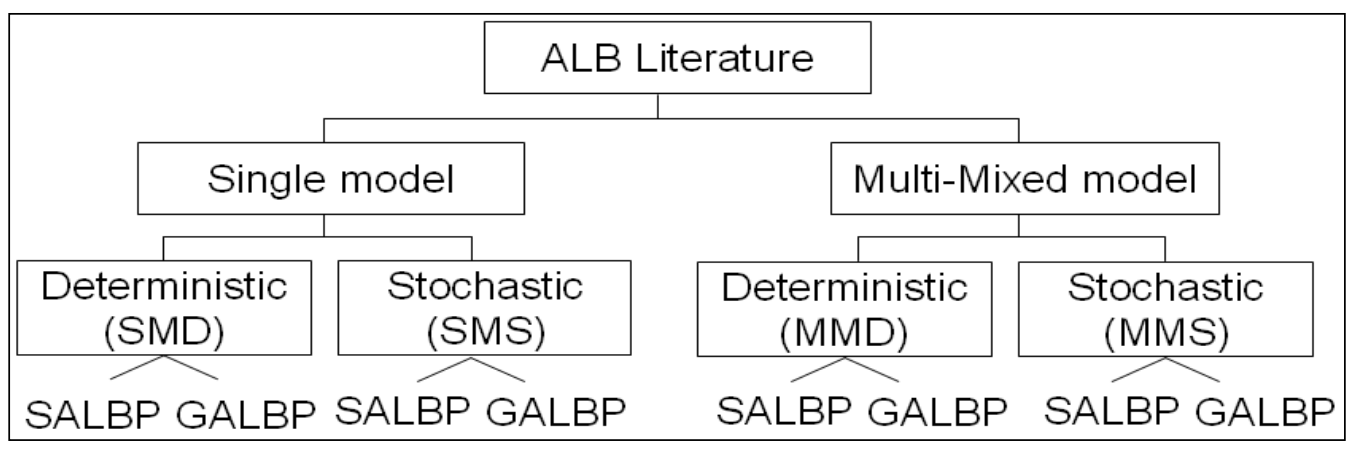

Fig. 3. Classification of assembly line balancing literature (Ghosh \& Gagnon, 1989) 


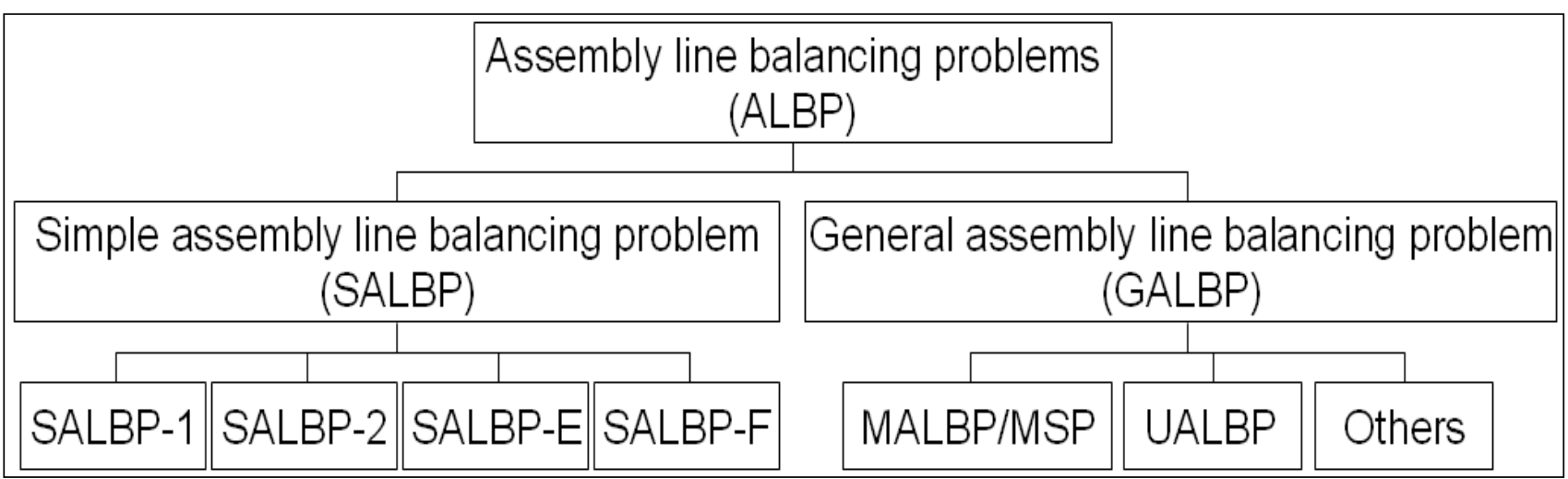

Fig. 4. Classification of assembly line balancing problems (Scholl \& Becker, 2006)

In the literature (Fig.3. and Fig.4.), all problem types which generalize or remove some assumptions of SALBP are called generalized assembly line balancing problems (GALBP). This class of problems is very large and contains all problem extensions that might be relevant in practice including equipment selection, processing alternatives, assignment restrictions etc (Becker \& Scholl 2006).

Assembly line balancing helps us avoid overproduction, inventory, transportation, motion, waiting, overemployment. With combination with other methods like MTM and UAS is possible to reduce Non-value Added Processing.

\section{Single assembly line balancing constraints}

Simple Assembly Line Balancing Problem (SALBP) has the following characteristics (Baybars 1986; Becker \& Scholl, 2006; Boysen et al. 2007):

- mass-production of one homogeneous product; given production process,

- paced line with fixed cycle time $c$,

- deterministic (and integral) operation times $t_{j}$,

- no assignment restrictions besides the precedence constraints,

- serial line layout with $m$ stations,

- all stations are equally equipped with respect to machines and workers,

- maximize the line efficiency Eff $=t_{\text {sum }} /(m . c)$ with total task time $t_{\text {sum }}=\sum_{j=1}^{n} t_{\mathrm{j}}$

The SALBP takes into account two constraints (either precedence constraints plus the cycle time, or the precedence constraints plus the number of workstations), it is by far the variant of line balancing that has been the most researched.

\section{Main descriptions assembly line balancing's restrictions}

The general input parameters of any Simple assembly line balancing problem (SALB) instance can be conveniently summarized and visualized by a precedence graph (Fig.5). This graph contains a node for each task, node weights which equal the task times and arcs reflecting direct as well as paths reflecting indirect precedence constraints. 


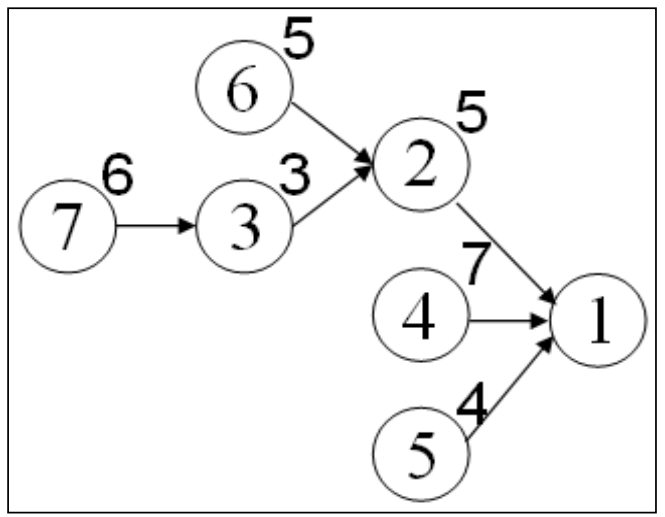

Fig. 5. Precedence graph

A feasible line balance, i.e. an assignment of tasks to stations has to ensure that no precedence relationship is violated. The set of tasks assigned to a station constitutes its station load, the cumulated task time is called station time. SALB further assumes that the cycle time of all stations is equal to the same value $c$.

\section{Main Approaches for solving Assembly line balancing problems}

There are different methods for solving assembly line balancing problems. Some are better for large assembly line, some are suitable for smaller assembly line. Selection of method may influence quality of received solution.

We distinguish the following main approaches for solving Assembly line balancing problems:

- Exact solution procedures.

- Heuristics - priority based procedures (descending task times, descending number of followers, ... ).

- Heuristics - search procedures (Tabu Search, Genetic algorithm, Ant colony approach, ...).

\section{Balancing algorithm in current tolls of digital factory - example DELMIA}

The Automatic Line Balancing process is logic based on the priority relations specified in the Priority Graph. A priority relation describes the order of processes. In Automatic Line Balancing, the ranking values are calculated on this basis. The ranking value is an abstract value used for calculation. The process times serve to calculate process ranking values.

There are two main aspects:

- Ranking value calculation according to the sum of successors,

- Ranking value calculation according to the maximum of successors. This calculation determines the critical path.

Advantage of tools DELMIA is good connection of Assembly line balancing with graphic environment (Fig. 6.) . 


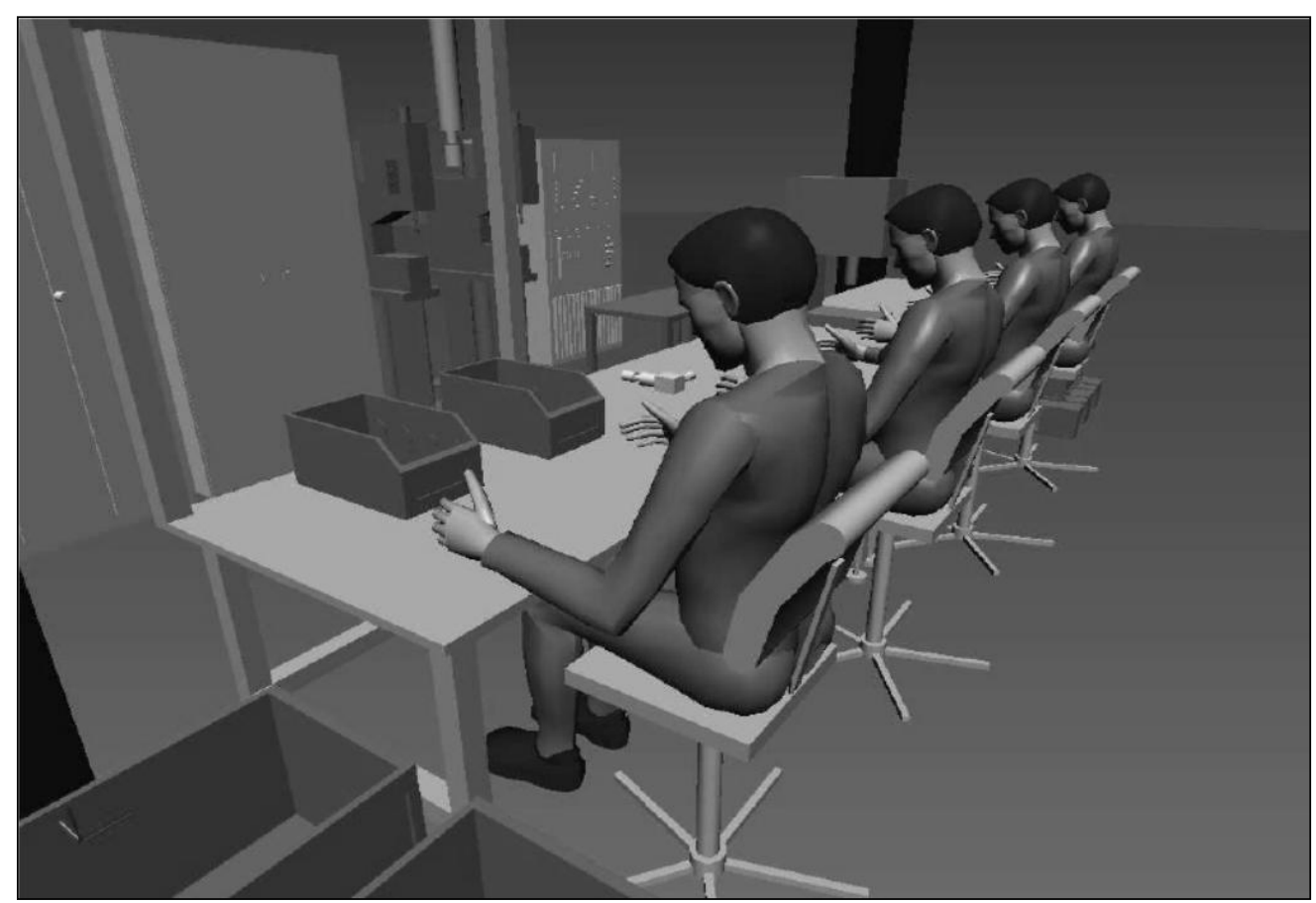

Fig. 6. Delmia Process Engineer - Assembly line

\section{Research and development}

On Department of manufacturing technology and materials in Zvolen with collaboration with Department of industrial engineering in Žilina, are investigated new possibilities of metaheuristics algorithm improvement for assembly line balancing. The features of research:

1. Development of new algorithm for assembly line balancing: New algorithms gain importance for automotive industry. With combinations with new progress tolls of digital factory, the new algorithm enables quick line balancing for automotive industry.

2. Focus on improvement of metaheuristics algorithms: Metaheuristics. The emergence of metaheuristics for solving difficult combinatorial optimization problems is one of the most notable achievements of the last two decades in operations research. Metaheuristic approach provides good and suitable solutions of the assembly line balancing (ALB) problems.

3. Integration of new algorithm into tools of Digital Manufacturing: Tools of digital factory are progressive technology, which has already been accepted in the most leading automotive manufacturers. Combination of new algorithm and tools of digital factory can contribute to the better solution of assembly line balancing problems.

4. Verification and Validation of proposed Algorithms: in praxis and comparison with other algorithms. This important part, which provides advantages and disadvantages of new algorithm and deliver best areas for its applications.

Limitations for this research represent the algorithms from metaheuristics family. Other forms of algorithm will be not investigated. Proposed algorithm will be proof using computational modeling. 


\section{Conclusion}

In this paper are presented assembly-lines balancing algorithms with focus on new research of ACO algorithms approach. The procedure minimizes the number of workstations of the line, as a major goal, and considers the additional goals of smoothing the workload between and within workstations. Future improvements of the algorithm should enforce probability at each stage. Development of an approach under a multi-objective perspective may be also useful to solve assembly line balancing problems.

\section{References}

Baybars, I. (1986). A survey of exact algorithms for the simple assembly line balancing problem. Management Science 32, 1986, pp.909-932

Becker, C. \& Scholl, A. (2006). A Survey on Problems and Methods in Generalized Assembly Line Balancing. European Journal of Operational Research. 2006, Volume 168, Issue 3: pp. 694-715

Boysen, N.; Fliedner, M. \& Scholl, A. (2007). A classification of assembly line balancing problems. European Journal of Operational Research 183, pp. 674693

Boysen, N.; Fliedner, B. \& Scholl, A. (2006). Assembly line balancing: Which model to use when? Wirtschaftswissenschaftliche Fakultät, ISSN 1611-1311, Available from: http://www.wiwi.uni-jena.de/papers/wp-sw2306.pdf , Accessed: 2011-08-30

Buzacott, J.A. \& Shanthikumar, J.G., (1993). Stochastic models of manufacturing systems. Prentice Hall, ISBN 0-13-847567-9, New York

Dolgui, A.; Ereemev, A.; Kolokolov \& A., Sigaev, V. (2002). A genetic algorithm for allocation of buffer storage capacities in production line with unreliable machines. Journal of Mathematical Modelling and Algorithms 1, pp. 89-104, 2002

Ghosh S. \& Gagnon, R.J. (1989). A Comprehensive Literature Review and Analysis of the Design, Balancing and Scheduling of Assembly Systems. International Journal of Production Research. (1989), Vol. 27, No.4: pp.637-670

Scholl, A. \& Becker, C. (2006). State-of-the-art Exact and Heuristic Solution Procedures for Simple Assembly Line Balancing. European Journal of Operational Research. 2006 Volume 168, Issue 3: pp. 666 - 693 , 2006

Scholl, A. (1999): Balancing and sequencing of assembly lines. 2nd ed., Physica, Heidelberg 1999

Zelenka, J. (2010): Discrete event Dynamic Systems Framework for Analysis and Modeling of Real Manufacturing System, CD zborník konferencie INES 2010, Lasp Palmas of Gran Canaria 2010, ISBN 978-1-4244-7651-0, IEEE Catolog Number: CFP10IES-CDR 